\title{
Hazardous or Not? Cannabis Use and Early Labor Market Experiences of Young Men
}

\author{
Jenny Williams * Jan C. van Ours ${ }^{\dagger \ddagger}$
}

April 26, 2020

\begin{abstract}
We study the relationship between cannabis use and early labor market experiences of young men, focusing on the time it takes them to find their first job, and the wage rate they receive at that job. We find that early cannabis users accept job offers more quickly and at a lower wage rate compared to otherwise similar males who did not use cannabis. These differences are present only for those who use cannabis for longer than a year before starting their job search. We also find that early cannabis users are less likely to return to education, and as a consequence, will have a lower educational attainment. Overall, our findings provide new insights into the direct and indirect relationships between cannabis use and early labor market experiences.
\end{abstract}

Keywords: multivariate duration models, discrete factors, cannabis use, job search, wages

JEL-codes: C41, I12, J01

Word count main text: 7749

${ }^{*}$ Department of Economics, University of Melbourne, Parkville, Australia and IZA (Bonn); email: jenny.williams@unimelb.edu.au. Williams is grateful to the Department of Economics at Tilburg University and IZA, who supported visits while this research was in progress.

${ }^{\dagger}$ Erasmus School of Economics, Erasmus University Rotterdam and Tinbergen Institute (Rotterdam), The Netherlands; Department of Economics, University of Melbourne, Parkville, Australia, CEPR (London) and IZA (Bonn); vanours@ese.eur.nl.

${ }^{\ddagger}$ The authors thank Mabel A. Andalón who set up a preliminary version of the data and Shannon Ward who set up the final version of the data used in this paper. We thank Peter Kuhn, Joe Sabia and Stefanie Schurer for providing valuable feedback on this research. Seminar participants at the IZA and the University of Queensland, and participants of the 2015 IAAE conference, the 2016 Risky Behaviors Conference, the 2019 Australian Econometrics and Health Economics Workshop, two anonymous reviewers and the editor of this journal also provided helpful feedback that has improved this research. 


\section{Introduction}

This paper investigates the potential hazards of cannabis use in terms of early labor market experiences. Our aim is to determine whether the cannabis use history that individuals have accumulated when they start searching for their first job is related to how quickly they find a job, and the wage rate they attract. Understanding the role that early cannabis use plays in youth successfully transitioning into work is both a relevant and significant margin from an economic perspective. In addition to affecting initial labor market outcomes, early cannabis use may have long lived effects through impacting on labor market trajectories (Altonji et al., 2014; Lundborg et al., 2014; Oreopoulos et al., 2012). Further, employment is an important determinant of well-being more broadly (Clark and Oswald, 1994; Schaller and Stevens, 2015). Despite this, little is currently known about whether initial labor market experiences differ for those who have used cannabis and those who have not, or about the relationship between cannabis use and labor market outcomes more broadly. Previous research has focused on the contemporaneous relationship between cannabis use, employment and wages. This research does not reach a consensus view, with studies reporting negative, positive and no wage effects of cannabis use, as well as negative or no effects on employment or hours worked (DeSimone, 2002; Kaestner, 1991, 1994b; Register and Williams, 1992; Van Ours, 2006, 2007). This makes it difficult to discern whether or not cannabis use is associated with hazardous labor market consequences, and if it is, the channels through which these hazards occur. It is in the context that we seek to make a contribution by providing new evidence on the relationship between cannabis use and early labor market experiences.

As with previous studies on the relationship between cannabis use and labor market outcomes, the key empirical challenge we face is disentangling the impact of cannabis use from unobserved confounding factors. In this research, we use the timing of events approach. Using a multivariate mixed proportional hazards (MMPH) framework, we jointly model the dynamics of cannabis use with the first spell of job search after completing education, and the wage rate at which a job offer is accepted. Cannabis use histories are permitted to influence the exit rate out of unemployment and the wage at which a job offer is accepted and job search ceases. Common unobserved confounders are accounted for by allowing for mixing of the distributions of unobserved heterogeneity terms affecting cannabis use dynamics and labor market outcomes.

Our framework has several advantages. First, it naturally accommodates the joint decision to cease job search and accept a job offer along with the wage at which this occurs. This provides a more complete and nuanced picture of the relationship between cannabis use and labor market outcomes than modeling either employment or wages alone, and avoids the practical issue of sample selection issues that typically plague the literature. A second advantage of the framework we use is that it allows for a richer investigation into the types of cannabis use histories that may be 
hazardous to early labor market outcomes. In particular, we are able to delve beyond a zero one measure of cannabis use and distinguish between experimental cannabis use and more substantial cannabis use histories. This is of particular salience because longer durations of use are strongly associated with adverse effects, including on mental and physical health, but not previously studied with respect to labor market outcomes (Anderson et al., 2013; Hall, 2015; Moore et al., 2007; Van Ours and Williams, 2011, 2012). A further advantage of our framework that it is straight forward to extend it to account for young adults increasingly common behavior of returning to school. By incorporating the option of exiting job search by returning to school into our empirical model, we are able to illuminate a previously unexplored channel through which cannabis use may effect educational attainment.

Our empirical investigation is based on information from the National Longitudinal Survey of Youth, 1997 cohort. These data are particularly well suited to our purpose, as the survey collects information on both cannabis use and the early labor market experiences of youth. Our analysis focuses on males since females are less likely to use cannabis (Carliner et al., 2017) and are less attached to the labor market (?). Our main findings are as follows. Early cannabis use is associated with less time spent in job search before accepting a job offer and a lower wage rate at which a job offer is accepted. These effects are driven by those who used cannabis for more than a year before starting their job search. We find no relationship between cannabis use and either the rate at which jobs are found, or the wage rate received when starting work for those who use cannabis for no more than a year before starting to search for their first job. Our findings are robust to accounting for the possibility that individuals end their search for their first job by returning to education rather than finding a job. This extended analysis also reveals that early cannabis users are less likely to return to school. This suggests that an important indirect mechanism through which early cannabis use is related to labor market outcomes is through lowering the likelihood of young men returning to school, and as a consequence, reducing their educational attainment.

Our contribution to the literature on the relationship between cannabis use and labor market outcomes is threefold. First, whereas previous studies analyze current labor market positions of individuals we focus on early labor market outcomes. This provides insights into the relationship between cannabis use and labor market outcomes at a particularly critical point in one of the most important transitions in the lives of young men. It also has the benefit of limiting the potential for reverse causality, i.e. high earnings having a positive effect on cannabis use. Second, not only do we model the relationship between cannabis use and job search and wages, we also allow for the possibility that cannabis use is related to the probability of returning to education. Thus, we provide a deeper understanding of the relationship between cannabis use and educational attainment. Third, we take the duration of cannabis use into account distinguishing between short 
term experimental use and longer term cannabis use. This gives us the opportunity to study a dimension of cannabis use previously unexplored in relation to labor market experiences of young men.

The set-up of the rest of the paper is as follows. In the next section we provide a conceptual framework by way of a discussion of the potential channels via which early cannabis use may be related to young man's transition into employment and discuss previous studies in the literature. Section 3 provides information about the NLSY97 data and descriptive statistics on cannabis use, job search, returning to school, and starting wages. In section 4 we discuss the set-up of our empirical analysis. Section 5 presents results from our baseline and extended analysis. Section 6 concludes.

\section{Conceptual Framework}

A useful framework for studying young men's first labor market experiences and illuminating potential channels through which early cannabis use may impact on these experiences is search theory. From a standard search theoretic perspective, the potential channels through which early cannabis use may impact on labor market outcomes are through its effects on individuals productivity, their value of leisure, and the extent to which they discount the future (Cahuc et al., 2014).

Cannabis use may affect a persons productivity by impacting on their mental or physical health, or their cognitive ability. There is some evidence that cannabis use is associated with poor mental health (Van Ours and Williams, 2011, 2012; Van Ours et al., 2013), physical health (Hall and Pacula, 2003) and lower IQ (Boccio and Beaver, 2017). If using cannabis does reduce labor market productivity through adversely impacting on mental health, physical health, or ability, then search theory predicts that the market wage of cannabis users will also be reduced. A lower expected wage will, in turn, reduce job search effort and hence lower the probability of employment. On the other hand, if cannabis use reduces stress (Childs et al., 2017) or is an alternative to opioid use for some acute or chronic health conditions (Bradford and Bradford, 2016; Park and Wu, 2017), and thereby facilitates working, it may increase productivity and hence wages and employment.

An alternate channel through which cannabis use may impact on early labor market outcomes is by increasing job seekers value of leisure, or increasing the rate at which they discount the future. A greater preference for leisure results in a reduced labor supply and a higher reservation wage (Kaestner, 1994a). As a result, the wage rate among employed cannabis users will be higher than otherwise similar nonusers. A further channel through which cannabis may impact on labor market outcomes is through increasing cannabis users' rate of time preference compared to nonusers (Becker and Murphy, 1988). In a simple search model, a higher rate of time preference lowers the 
reservation wage and decreases search effort, with the net effect of increasing the transition rate into employment (DellaVigna and Paserman, 2005). Of course, it may be that individuals with a higher value of leisure, or who discount the future more heavily, self-select into cannabis use. If this is the case, then cannabis use is a consequence, rather than a cause, of these characteristics. Currently, research is unclear on this point (Aston et al., 2016; McDonald et al., 2003; Sferra et al., 2015; Volkow et al., 2016). This highlights the need to account for selectivity into cannabis use in modeling its effect on labor market outcomes.

Comparing these predictions with the findings from the literature on the effect of cannabis use on labor market outcomes should provide insights into which of the potential channels are likely to be important. Several studies from the US based on the NLSY tend to suggest that cannabis use increases wages and reduces employment or hours worked, which is consistent with cannabis use increasing users' value of leisure (DeSimone, 2002; Kaestner, 1991; Register and Williams, 1992). In contrast, Van Ours (2007) and Van Ours (2006) studying cannabis use and labor market outcomes in Amsterdam, finds that cannabis use reduces wages but is unrelated to employment. Similarly, Sabia and Nguyen (2018) find that the enactment of medical marijuana laws in the US is associated with an increase in cannabis use and a decline in hourly wages of men in their 20's, but no effect on employment. These studies may indicate that cannabis use reduces productivity or perhaps leads to greater discounting of the future. On the other hand Kaestner (1994a) and Kaestner (1994b) find that cannabis use has no effect on either wages nor employment, which suggest no harmful labor market effects of cannabis use.

Overall, past studies do not provide a clear sense as to the relationship between cannabis use and labor market outcomes. It is worth noting that this may in part be due to differences in empirical approaches. For example, while DeSimone (2002); Kaestner (1991); Register and Williams (1992) Kaestner (1994a) and Kaestner (1994b) all use the NLSY, the first three studies use a crosssectional IV approach whereas the latter two use longitudinal data and combine fixed effects and IV estimation, and these two approaches rely on differing and untestable identifying assumptions. Further the analyses of Van Ours (2007) and Van Ours (2006) are not only based on a different empirical approach, the timing of events approach which is subject to its own set of identifying and ultimately untestable assumptions, these studies also use data from a different country, the Netherlands, which has a considerably different institutional setting. ${ }^{1}$ Therefore, different empirical

\footnotetext{
${ }^{1}$ Instrumental variables and the timing of events, which is typically implemented within a multivariate mixed proportional hazard framework, are the two main approaches to addressing the issue of endogenous selection into cannabis use in the literature. Instrumental variables and the timing of events approach rely on different untestable assumptions in order to isolate the causal parameter of interest. A discussion of these assumptions in the context of the literature on the labor market effects of cannabis use is provided by Van Ours and Williams (2015). An exception is Kagel et al. (1980) who use a field experiment to study the impact of cannabis use on work performance. As innovative as the design of this study is, it is nonetheless subject to limitations, due to both sample selection and design constraints, as discussed by the authors.
} 
approaches and the validity of identifying assumptions underpinning these approaches, differences in data and in institutional settings may all contribute to differing empirical findings. To the extent that identifying assumptions may not be satisfied, caution is required in interpreting the literature as providing reliable estimates of causal effects. More generally, the mixed evidence from the past investigations highlight the need for further efforts to establish whether cannabis use poses a hazard to economic health, as measured by labor market success.

\section{Data}

\subsection{NLSY97}

Our analysis is based on males from the National Longitudinal Survey of Youth 1997 (NLSY97). The NLSY97 is a longitudinal survey representative of American youths who were 12-16 years old as of 31 December 1996. It is designed to capture educational and early labor market experiences of youth, but also collects detailed information on cannabis use. The first round of the survey was fielded in 1997 and 1998. Subsequent rounds of the survey have been conducted annually, and the retention rate for wave 15 , fielded in 2011 , is $85.6 \%$. The interviews are conducted using a computer-assisted personal interview instrument, administered by an interviewer with a laptop computer. The mode of interview is in person or by telephone. When interviews were conducted in person, the information on substance use was self-administered. Personal interviews constitute the bulk of data. Our sample comprises 3,855 males who answer questions about cannabis use in at least one round of the survey, report not being enrolled in education (for at least 3 months) in at least one round, and for those who report starting a job, provide information on their wage. The age range in our sample, 12 to 18 in 1997 through to 26 to 32 in 2011, covers the periods in the life cycle during which cannabis uptake and the transition to work typically occur. ${ }^{2}$

\subsection{Labor Market Outcomes}

We focus on young men's first post education job search. The duration of time spent searching for employment is constructed by first calculating the number of months that elapsed from the month the respondent left education until the month he reports starting employment at a new job. Individuals are considered to have left education in the first month they report not being enrolled and not being on vacation, expelled or suspended in school, college or other educational institution. To ensure that we do not include summer vacations as exits from education, we additionally require that an exit has a length of time not enrolled in study of at least 3 months. Durations of job search are censored for individuals who return to education before finding an eligible job or who had not

\footnotetext{
${ }^{2}$ Web Appendix A1 provides more details on our data.
} 
found a job when they were last interviewed. The duration of search until first job is defined in terms of quarters of years and constructed by dividing the months taken to find a job by three. The wage rate at which a job is accepted is measured by the first job's initial hourly wage excluding overtime pay or commissions. Information on the hourly wage for people who are paid by the hour is based on the question: "What was your hourly rate of pay when you first started this job?" For those who were not paid hourly, weekly earnings were divided by hours worked per week to obtain the hourly wage rate.

Our extended analysis models the hazard rate of returning to education. For those who return to education rather than start work, the duration of time until returning to education is defined as the number of months elapsed from the month they first exited education to the month that they returned to education. Note that the minimum duration until returning to education is 3 months, since the definition of an exit from school requires individuals to not be enrolled for at least 3 months. We convert the duration until returning to education from months to quarters of years. ${ }^{3}$

\subsection{Dynamics of Cannabis Use}

In our analysis of the dynamics of cannabis use, we model both the age at first use and the duration of use among users. The age at first use is self-reported for those who report having ever used cannabis in wave 1. For individuals who do not report using in wave 1, the age at first use is based on information provided in subsequent waves on whether the respondent had used cannabis since the date of the last interview (SDLI). The duration of use is calculated using information on the age at which the respondent last reported cannabis use combined with the age at first use. The focus of our study is on young men's cannabis use and the duration of that use, before they enter the labor market for the first time. The indicator for cannabis use is defined to be equal to one if initiation into cannabis use occurs prior to commencing job search, and zero otherwise. The duration of cannabis use before commencing job search is constructed using information on age at first use, age at last use, and the age at which the respondent exits education and commences job search (for the first time). ${ }^{4}$

\subsection{Descriptive Statistics}

Table 1 provides descriptive statistics on the key variables for the sample of 3885 males we use in our analysis. In the second and third column we report descriptive statistics for two samples. The second column reports statistics for respondents who did not use cannabis before they entered the labor market and began to search for a job. The third column reports statistics for respondents

\footnotetext{
${ }^{3}$ Web Appendix A2 provides more descriptives on the labor market outcomes.

${ }^{4}$ Web Appendix A3 provides more descriptives on the dynamics of cannabis use.
} 
who did use cannabis before they entered the labor market and began to search for a job. The table shows that $63 \%$ of our sample have used cannabis in the sample period, and that $43 \%$ used cannabis before they began their job search. Forty-nine percent of the sample used cannabis before finding a job, which means that $6 \%$ started cannabis use in the period spent searching for their first job (or, for those who did not find a job, before leaving the sample or returning to education). Given that most of the people who have used cannabis before finding a job started use before they began their job search, we model the job search process as a function of cannabis use before entering the labor market. Modeling job search as a function of cannabis use before finding a job would yield similar results because only a small percentage of people initiate into cannabis use after they left education and before finding a job.

Among those who have ever used cannabis, the average age at first use is 16.6 years of age. Table 1 also shows that the average duration of use when entering the labor market among those who had previously initiated is 3.8 years. The average total duration of use (measured when they last responded to the survey) among those who initiated before entering the labor market is 7.4 years, compared with 4.3 years for those whose uptake occurred after they started their job search. In terms of education, sample members leave school (for the first time) on average at around 18.7 years of age, with 12.1 years of education.

With respect to labor market outcomes, Table 1 shows that, among those who begin working, cannabis users take 0.4 fewer quarters (on average) to find a job and earn a slightly higher initial wage, although the difference in hourly wage rates is not statistically significant. Table 1 also shows that $18 \%$ of the men in our sample exit unemployment by returning to education rather than finding a job. Cannabis users are less likely to go back to education (before finding a job) than non-cannabis users (14\% compared to $21 \%$ ). Conditional on going back to education the average duration until returning to education is 4.1 quarters, or just over one year.

In our sample, when individuals enter the labor market for the first time, those with a cannabis using history have completed 12.2 years of education compared to 12.0 years among those who had not used cannabis. At the time we last observe individuals in our sample, those who used cannabis before entering the labor market have completed 13.1 years compared to 13.4 years among those who had not used cannabis. After controlling for individual, family and other characteristics, the difference between educational attainment when first leaving education between those who did and did not use cannabis is -0.03 and statistically insignificant $(p$-value $=0.60)$, whereas the last time we observe them (after accounting for returning to education), the difference between educational attainment is a statistically significant -0.32 of a year $(p$-value $=0.000)$. This suggests that it is a difference in returning to education that explains why cannabis users complete fewer years of education. Our extended analysis accounts for the decision to return to education, and how it is 
influenced by cannabis use. In doing so we address an important avenue through which cannabis use may be related to educational attainment, and hence indirectly effect future labor market outcomes.

\section{Set-up of the empirical analysis}

The main challenge in establishing the impact of cannabis use on young men's first transitions into work is that both selection into cannabis use and transitions into employment may be affected by circumstances and characteristics that are not observed. These common unobserved 'confounding' factors may be a source of spurious association and must be accounted.

In this paper, we address the potential for endogenous selection into cannabis within a multivariate mixed proportion hazards framework $(\mathrm{MMPH})$ framework by modeling the correlated distribution of unobserved heterogeneity on which selection is based non-parametrically using a discrete factor approximation (Abbring and Van den Berg, 2003; Gaure et al., 2007; Heckman and Singer, 1984; Mroz, 1999). Estimation is via non-parametric maximum likelihood estimation (NPMLE). The main advantages of the discrete factor approach in our application are that it provides reliable estimates in models with endogenous variables without imposing arbitrary distributional assumptions on the unobserved heterogeneity, it retains the efficiency of maximum likelihood estimators, and it does not rely on instrumental variables which are difficult to find. This approach has previously been used in a wide variety of applications in health and labor economics (see for example, Cutler (1995); Bray (2005); Van Ours (2006, 2007); Yang et al. (2009)). ${ }^{5}$ Identification of the causal parameters of interest relies on the timing of events (in our application, cannabis use precedes entry into job search) and assumptions about functional form. The functional form assumptions are that the hazard rates have a proportional function form and unobserved heterogeneity is time-invariant and uncorrelated with the control variables. Duration dependence and unobserved heterogeneity are modeled non-parametrically.

As with all approaches to identifying causal parameters using observational data, the approach we employ relies on identifying assumptions that are untestable. It is therefore important to consider the extent to which the identifying assumptions are reasonable in the context that we study, and understand the limitations they impose. Specifically, the assumption of time-invariant unobserved heterogeneity may be reasonable if we think of it as capturing temperament or traits, such conscientiousness, that tend to be stable over time (Cobb-Clark and Schurer, 2012, 2013; Elkins

\footnotetext{
${ }^{5}$ In a Monte-Carlo evaluation of discrete factor approximations in simultaneous models Mroz (1999) found that when the true distribution of unobserved heterogeneity is not known, and in the absence of instruments, the discrete factor approximation outperformed two-stage least squares and MLE estimators that attempted to control for endogeneity.
} 
et al., 2017). However, it cannot accommodate unobservables that vary over time and influence both cannabis use and job search behavior, such as ambition, and this is an important limitation. This caveat should be borne in mind when interpreting our estimates as causal. ${ }^{6}$

\subsection{Job finding and Starting Wages}

We focus on two inter-related aspects of the transition into work for the first time: (1) the time it takes to find a job and (2) the initial wage rate for the first job. For clarity of exposition, we introduce our approach by modeling these processes as independent, and treating cannabis use before entering job search as exogenous. These assumptions are relaxed in estimation.

Beginning with the transition from post education unemployment to employment, differences in the rate at which individuals find a job are assumed to depend on a vector of observed characteristics which includes an indicator for using cannabis before starting job search, $x_{j}$, the elapsed duration of time unemployed, $t^{j}$ and unobserved characteristics, $\nu^{j}$. The starting rate for job finding at time $t^{j}$ conditional on observed characteristics, $x_{j}$ and unobserved characteristics, $\nu^{j}$ is specified as a mixed proportional hazard given by

$$
\theta^{j}\left(t^{j} \mid x_{j}, \nu^{j}\right)=\lambda^{j}\left(t^{j}\right) \exp \left(x_{j}^{\prime} \beta_{j}+\nu^{j}\right)
$$

where $\lambda^{j}\left(t^{j}\right)$ represents duration dependence, which is modeled flexibly using a step function

$$
\lambda^{j}\left(t^{j}\right)=\exp \left(\Sigma_{k} \lambda_{k}^{j} I_{k}\left(t^{j}\right)\right)
$$

where $k(=1, \ldots, \mathrm{N})$ is the subscript for the number of elapsed time intervals since entering unemployment and $I_{k}(t)$ are time-varying indicators variables for consecutive intervals. These intervals are specified in terms of individual quarters ( 3 month periods) for quarters 1 through to 14 , an interval from quarter 15 through to quarter 25, and the last interval is for quarter 26 onward. Because a constant term is estimated, $\lambda_{1}^{j}$ is normalized to 0 .

The conditional density function for the completed duration of unemployment until finding a job is

$$
f^{j}\left(t^{j} \mid x_{j}, \nu^{j}\right)=\theta^{j}\left(t^{j} \mid x_{j}, \nu^{j}\right) \exp \left(-\int_{0}^{t^{j}} \theta^{j}\left(j \mid x_{j}, \nu^{j}\right) d j\right)
$$

Individuals who have not found employment by the end of the observation period are assumed

\footnotetext{
${ }^{6}$ Identification would be strengthened by exclusion restrictions. This requires variables that influence cannabis uptake and quitting but not job search behavior and vary over time. Potential candidates include state level cannabis laws and cannabis prices and child labor laws.
} 
to have a right-censored duration of time until finding a job. Integrating out the unobserved heterogeneity component, we obtain the duration until job finding conditional on $x_{j}$ as:

$$
f^{j}\left(t^{j} \mid x_{j}\right)=\int_{\nu^{j}} f^{j}\left(t^{j} \mid x_{j}, \nu^{j}\right) d H\left(\nu^{j}\right)
$$

where $H\left(\nu^{j}\right)$ is assumed to be a discrete distribution with $g$ points of support. In the empirical application, we are able to identify two points of support for this distribution, implying that (conditional on observed characteristics) there are two types of individuals: the first type have a high rate of job finding (and so leave unemployment relatively quickly), while the second type have a lower rate of job finding (and so spend longer in unemployment). The associated probabilities, denoted $\operatorname{Pr}\left(\nu^{j}=\nu_{1}^{j}\right)=p_{1}$ and $\operatorname{Pr}\left(\nu^{j}=\nu_{2}^{j}\right)=1-p_{1}$, are modeled using a logit specification.

Individuals who accept a job offer do so at the initial wage offer. The log (hourly) wage rate received upon accepting a job offer and starting employment is modeled using the standard human capital approach as follows:

$$
w=x_{w}^{\prime} \beta_{w}+\nu^{w}+\epsilon, \quad \text { where } \epsilon \sim \text { iid } N\left(0, \sigma^{2}\right)
$$

where the error term is composed of the unobserved heterogeneity term $\nu^{w}$ and the idiosyncratic shock, $\epsilon \sim$ iid $N\left(0, \sigma^{2}\right)$, and $x_{w}$ consists of observed determinants of wages, including an indicator for whether cannabis was used before starting job search. We assume $\nu^{w}$ is drawn from a discrete distribution with 2 points of support. The associated probabilities, $\operatorname{Pr}\left(\nu^{w}=\nu_{1}^{w}\right)=p_{2}$ and $\operatorname{Pr}\left(\nu^{w}=\right.$ $\left.\nu_{2}^{w}\right)=1-p_{2}$, are modeled using a logit specification which allows us to integrate out the unobserved heterogeneity from the wage equation.

\subsection{Cannabis use dynamics}

We assume that the hazard of starting and quitting cannabis use each have a mixed proportional hazard and specify the joint density function of the duration until cannabis uptake and the duration until quitting cannabis use conditional on observed determinants of uptake and quitting ( $x$ and $z$, respectively) as

$$
f^{s q}\left(t^{s}, t^{q} \mid x, z\right)=\int_{u^{q}} \int_{u^{s}} f^{s}\left(t^{s} \mid x, u^{s}\right) f^{q}\left(t^{q} \mid z, u^{q}\right) d G\left(u^{s}, u^{q}\right)
$$

where $f^{s}\left(t^{s} \mid x, u^{s}\right)$ is the conditional density for completed durations until starting cannabis, $f^{q}\left(t^{q} \mid z, u^{q}\right)$ is the conditional density for completed durations of cannabis use, and $G\left(u^{s}, u^{q}\right)$ is a discrete distribution with an unknown number of points of support that accounts for correlation in unobserved heterogeneity in uptake and quitting decisions. In practice, we are able to identify 
three points of support in the joint distribution, $\left(u_{1}^{s}, u_{1}^{q}\right),\left(u_{1}^{s}, u_{2}^{q}\right),\left(u_{2}^{s}\right)$, with $u_{2}^{s}=-\infty$ implying a zero starting rate. The specification of the distribution of unobserved heterogeneity implies that conditional on the observed personal characteristics (including age and duration of use) there are three types of individuals. The first type represents the "experimenters" who have a positive starting rate and a high quit rate. The second type represents the "persistent users" who have a positive starting rate and a low quit rate. Individuals in this group use cannabis for longer than those in the first group. The third type are "abstainers". They have a zero starting rate, and therefore their quit rate is non-existent. The associated probabilities are denoted as

$$
\operatorname{Pr}\left(u^{s}=u_{1}^{s}, u^{q}=u_{1}^{q}\right)=p_{3} \quad \operatorname{Pr}\left(u^{s}=u_{1}^{s}, u^{q}=u_{2}^{q}\right)=p_{4} \quad \operatorname{Pr}\left(u^{s}=u_{2}^{s}\right)=p_{5}
$$

and are assumed to have a multinomial logit specification with $p_{n}=\frac{\exp \left(\alpha_{n}\right)}{\Sigma_{n} \exp \left(\alpha_{n}\right)}$, with $n=3,4,5$ and $\alpha_{5}$ normalized to zero. Details of the specification of the likelihood are given in Web Appendix B1.

Note that we have described the three components: (1) the hazard for starting work; and (2) the wage equation; and (3) cannabis use dynamics; as independent of one another. Our empirical strategy begins by mirroring this description, estimating each component as an independent process before relaxing the assumption of independence between the components, allowing for fully correlated unobserved heterogeneity. Conflating the three types of individuals (based on their unobserved heterogeneity) found in the cannabis dynamics, the two types found in the job finding and the two types found in the wage equation produces a distribution of unobserved heterogeneity with up to 12 points of support in the fully correlated system of four equations.

\section{$5 \quad$ Parameter estimates}

\subsection{Baseline analysis}

Table 2 presents estimates on the relationship between cannabis use and job finding and initial wages. ${ }^{7}$ The parameter estimates are obtained using the method of non-parametric maximum likelihood, and account for the fact that our duration information relates to intervals rather than to exact durations. Panel $a$ reports estimates assuming that job finding, wages and cannabis dynamics are independent. Panel $b$ reports estimates in which we permit the unobserved heterogeneity determining cannabis use dynamics and labor market outcomes to be drawn from a fully correlated joint distribution, thereby accounting for endogenous selection into cannabis use in the job findings and wage equations. The lower part of Table 2 shows the distribution of unobserved heterogeneity for this specification. As indicated, we identify 12 points of support in the distribution of unob-

\footnotetext{
${ }^{7}$ The full set of estimates from modeling cannabis use dynamics and job finding and initial wages, assuming independent processes are reported in Web Appendix Tables C.1 and C.2, respectively.
} 
served heterogeneity. An LR-test rejects the null hypothesis that the unobserved heterogeneity is independent (The LR-test comparing the results in Table 2 panel a1 and a2 with panel b has a value of 53.2 whereas critical $\left.\chi_{7}^{2}(\alpha=0.05)=18.5\right)$. This confirms that selection into cannabis use before entering job search is endogenous.

Comparing the results in panels $a$ and $b$ shows that accounting for the endogenous selection into cannabis use reduces the magnitude (and statistical significance) of the effect of cannabis use on the duration of time it takes young men to find their first job, and the starting wage in their first job. Specifically, cannabis use before entering job search is estimated to increase the job finding rate by $14 \%$ when selection into cannabis is ignored, and increase the job finding rate by $8 \%$ when it is accounted for. Similarly, the magnitude of the estimated effect of cannabis use before entering job search on the starting wage of the first job is reduced from $1.9 \%$ when selection into cannabis use is ignored, to $1.7 \%$ when selection is accounted for. Moreover, accounting for selection into cannabis use produces less precise estimates, with the effect on job finding remaining weakly significant (at the $10 \%$ level) while the effect on wages becoming statistically insignificant at conventional levels (with a t-statistic of 1.5).

Inspection of the distribution of unobserved heterogeneity for this specification confirms that most individuals are of a type that is characterized by being susceptible to having a relatively low wage $(35.5 \%+34.8 \%+25.1 \%=95.4 \%)$. In terms of cannabis types, $37.1 \%(=1.6 \%+35.5 \%)$ are susceptible to experimenting with cannabis, $36.3 \%(=1.5 \%+34.8 \%)$ are susceptible to longer term use, and $26.6 \%(=1.4 \%+25.2 \%)$ are not susceptible to using cannabis. Among those vulnerable to having a low wage type, the most commonly represented types are those who have a high susceptibility to finding a job and a vulnerability to cannabis use, who account for $60.6 \%(=30.1 \%$ $+30.5 \%$ ) of the sample. In terms of cannabis user types, of this $60.6 \%$, experimenters and persistent users are equally represented (30\% are experimenters and $31 \%$ are persistent users). The balance of this low wage high job finding group, $19 \%$ of the full sample, are not susceptible to cannabis use. Among the low wage and low job finding group, experimenters, persistent cannabis users and non-users are fairly equally represented, contributing $5.4 \%, 4.3 \%$ and $6.4 \%$, respectively, to the $16 \%$ of the sample in this group. Similarly, experimenters, persistent users and non-users are equally likely among the $5 \%$ who are inclined to be in the high wage group, with respective probabilities of $1.6 \%, 1.5 \%$ and $1.4 \%$ of the full sample.

A possible source of heterogeneity with respect to the effects of cannabis use on labor market outcomes is the level of education with which young men enter job search. Some males drop out of high school and then searching for a job, some complete high school before starting their job search, while other complete college before entering the labor market. It is possible that the effects of cannabis use depend on the level of education with which you enter job search. To investigate this 
potential source of heterogeneity we estimate an extended model that includes interactions between cannabis use and indicators for level of educational attainment (highest level of attainment is less than a high school graduate; high school graduate; college graduate) in the job finding and wage equations. As shown in panel $c$ of Table 2, for males who left school before graduating high school, the effect of cannabis use on the job finding rate is significantly positive whereas for those whose educational attainment is high school graduate or college graduate, the effect of cannabis use on job finding is small and insignificant. The wage effects of cannabis use are all negative but insignificantly different from zero for all levels of educational attainment. These results suggest that may be heterogeneity by educational attainment in the effects of cannabis use, with higher transition rates into employment for those with less than a high school diploma. However, the LR-test statistic comparing the estimation results in panels $b$ and $c$ is equal to 4.0 which is not statistically significant (the critical $\left.\chi_{4}^{2}(\alpha=0.05)=7.8\right)$. Therefore, we cannot reject the hypothesis of no education-specific effects of cannabis use.

Panels $d$ and $e$ of Table 2 seek to provide a more nuanced understanding of for whom cannabis use before entering job search matters by investigating whether there exist differences by age at first use (panel $d$ ) and by whether use is experimental (no more than 1 year of use before leaving education) or non-experimental (more than a year before leaving education) in nature (panel $e$ ). The estimates in panel $d$ suggest that the results for cannabis use are driven by uptake at ages 16 to 17. However, the LR test comparing specifications $b$ and $d$ fails to reject the null hypothesis of homogeneous effects by age of uptake (The LR test statistic is 1.8, which is smaller than the critical $\left.\chi_{2}^{2}(\alpha=0.05)=6.0\right)$. In contrast, the LR test comparing specifications in panel $b$ and $e$ rejects the null hypothesis that experimental (no more than a year) and non-experimental cannabis use (greater than a year) before entering job search have similar effects on labor market transitions. In particular, the results from estimating the model allowing for differential effects finds that using cannabis for no more than a year before entering job search is not related to either the rate at which young men find their first job, or the wage rate at which they accept their first job. In contrast, using cannabis for longer than a year increases the job finding rate by $13 \%$ compared to an otherwise similar individual who had not used cannabis before entering job search (or did so for no more than a year), and reduces the wage rate received when starting their first job by $2 \%$ compared to their non-cannabis using counterparts. Reflecting on our earlier discussion of the potential channels through which cannabis use is related to labor market outcomes, our findings point to non-experimental use of cannabis increasing the rate at which young men discount the future. That is, cannabis use make young men more impatient with respect to getting their first job. 


\subsection{Accounting for Returning to Education}

A significant proportion of young men in our sample exit unemployment not through finding a job, but by returning to education. We account for this by replacing the job finding hazard in the four equation system with a competing risk model in which there are two ways in which the period of job search after first leaving education can end. Individuals can either find a job or they can return to education. The competing risk model is specified as a special case of a bivariate mixed proportional hazard model with flexible duration dependence.

Transitions to employment are modeled as previously described. Transitions back to education are modeled symmetrically, with the rate at which males return to education, $\theta^{r}$, given by

$$
\theta^{r}\left(t^{r} \mid x_{j}, \nu^{r}\right)=\lambda^{r}\left(t^{r}\right) \exp \left(x_{j}^{\prime} \beta_{r}+\nu^{r}\right)
$$

where $\lambda^{r}\left(t^{r}\right)$ represents duration dependence, which is modeled flexibly using the same step function as for the duration dependence of the job finding rate.

The conditional density function for the completed duration until finding a job or returning to education is

$$
f^{j r}\left(t \mid x_{j}, \nu^{j}, \nu^{r}\right)=\left(( \theta ^ { j } ( t | x _ { j } , \nu ^ { j } ) + \theta ^ { r } ( t | x _ { j } , \nu ^ { r } ) ) \operatorname { e x p } \left(-\int_{0}^{t}\left(\left(\theta^{j}\left(y \mid x_{j}, \nu^{j}\right)+\theta^{r}\left(y \mid x_{j}, \nu^{r}\right)\right) d y\right)\right.\right.
$$

The duration of stay in unemployment is determined by the sum of the two transition rates $\theta^{j}\left(t \mid x_{j}, v^{j}\right)$ and $\theta^{r}\left(t \mid x_{j}, v^{r}\right)$. Identification of the separate transition rates in the competing risk model comes from the nature of the transition, to a job or back to education. Web Appendix B2 provides details of the specification of the likelihood.

Table 3 panel $b$ reports non-parametric maximum likelihood estimates of the relationship between experimental and persistent cannabis use and the first labor market transition of young men accounting for the competing risk of returning to education. Panel $a$ repeats the estimates from Table 2 panel $d$, in which the option of returning to school is ignored. As can be seen from the reported estimates, accounting for the fact that a significant proportion of the sample exits unemployment by returning to education produces stronger effects of non-experimental cannabis use both in terms of magnitude and significance. The point estimate of the coefficient on cannabis use for more than a year in the hazard for job finding increases from 0.12 to 0.17 , implying an increase in the estimated job finding rate from $13 \%(100(\exp (0.12)-1))$ to $19 \%(100(\exp (0.17)-1))$ relative to non-cannabis users. The higher rate of job finding by non-experimental users comes at the cost of a wage rate that is $2.0 \%$ lower based on estimates that ignore the option of returning to education, 
and $2.3 \%$ lower if returning to education is accounted for. In addition, for the specification that incorporates the competing risk of returning to education, the coefficient estimates suggest that both experimental and non-experimental cannabis use reduces the likelihood of returning to education.

While those who use cannabis are more likely to exit unemployment by getting a job compared to non-cannabis users, a more careful examination of the behavior of young men following exiting education reveals that this is partly because cannabis users are more likely to be employed before returning to education compared to non-cannabis users. For example, among those who return to education within a year, $44 \%$ of cannabis users and $38 \%$ of non-cannabis users first had a job. It is questionable whether these temporary "gap year" jobs are part of a genuine transition to employment. Moreover, since there are differences in this behavior between those who use cannabis and those who do not, failing to address this issue may result in misleading and unreliable estimates of the relationship between cannabis use and the transition to employment. Therefore, to put cannabis users and non-cannabis users who return to education (relatively quickly) on a more equal footing, we re-estimate the model that accounts for returning to education, but this time we ignore jobs for individuals who return to education within a year (of exiting education for the first time). The results from this estimation are reported in Table 3 panel $c$. They show that, by focusing on jobs that are not short-term "gap year" jobs, the relationship between non-experimental cannabis use and the transition to work is in fact strengthened, with non-experimental cannabis use increasing the job finding rate by $32 \%(\exp (0.28)-1)$, and decrease the starting hourly wage rate by $2.6 \%$.

A final issue we examine is whether our findings are sensitive to defining the transition to work in terms of any employment or full-time employment only. Up until this point, any job that had a start month that occurred after the month the respondent left education has been considered a transition to work. The only exception to this is found in panel $c$ of Table 3 , for which "gap year" jobs were ignored. We examine the sensitivity of our findings by restricting our definition of employment to jobs in which the respondent worked 35 hours or more per week on average. The results from estimation, reported in panel $d$ of Table 3, produce coefficient estimates for the indicator for using cannabis for more than a year before entering unemployment that are similar to those reported in Table 3 panel $c$, and are consistent with earlier findings that experimental cannabis use has no significant effect on the transition to work, non-experimental cannabis use is associated with finding a job more quickly and with lower wages, and any cannabis use, experimental or not, reduces the likelihood of returning to education. 


\section{Discussion}

We investigate the relationship between early cannabis use and young men's first transition into employment. The two dimensions of this transition that we focus on are the duration of time spent searching before fining employment for the first time, and the wage rate received when starting the first job. Our empirical approach accounts for selection into cannabis use by modeling timeinvariant unobserved heterogeneity that jointly affects the hazard rate of job finding, the initial wage rate and cannabis use dynamics. To the extent that the identifying assumptions on which our approach is based are met, our parameter estimates of the effect of cannabis use on job search and starting wages can be interpreted as causal. Nonetheless, the reliance on assumptions that are not testable for identification of causal effects of cannabis use is an important limitation of this study, and suggests that a cautious approach to interpreting our findings may be warranted.

Our baseline results find that early cannabis use is associated with shorter durations of unemployment. This comes at the cost of lower wages, with those who use cannabis accepting a slightly lower hourly wage compared to those who do not use cannabis. However, the association of cannabis on the rate at which young men find jobs and the initial wages in the first post education job is present only for those who used for a period of more than a year before entering unemployment and beginning their search for a job. Experimenting with cannabis use for up to a year before entering unemployment does not seem to be associated with young men's early labor market experience. Viewed from a search theoretic perspective, these findings suggest the channel through which early non-experimental use of cannabis is related to young man's first transition into employment is through increasing the rate at which they discount the future.

In addition to extending the previous literature on the effects of cannabis use by studying early labor market experiences, and whether use is experimental or longer term, we provide new insights into the indirect role of cannabis use on labor market success by accounting for young men exit job search by returning to school. Doing so strengthens our findings on the relationship between cannabis use and job search behavior, and reveals that early cannabis users are less likely to return to education. These findings provide new insights into pathways via which cannabis use reduces educational attainment.

If we take our preferred parameter estimates presented in panel $b$ of Table 2 at face value and assume that they can be interpreted causally, they provide an indication of the possible magnitude of the effects. Non-experimental cannabis use (i.e. more than 1 year) increases the job finding rate by almost $19 \%\left(100^{*} \exp (0.17)-1\right)$ while the rate of returning to education is reduced by almost $38 \%$ $(100 * \exp (-0.47)-1)$. If we assume the job finding rate in the first year to be on average equal to $20 \%$ per quarter for non-cannabis users, our estimates suggest that it would be $24 \%$ for cannabis users.

Similarly if we assume the rate of return to education in the first year to be on average equal to 
$8 \%$ per quarter for non-cannabis users, it would be $5 \%$ for cannabis users. So, although the overall exit rate from unemployment after 1 quarter is similar for non-experimental cannabis users and non-cannabis users (29\% versus $28 \%$ ), the composition of the exit is quite different. In addition, non-experimental cannabis users accept job offers with starting wages that are $2.3 \%$ lower than otherwise similar young men who have not used cannabis.

We conclude that non-experimental cannabis users seem to find a job more quickly but at a lower wage, and also seem to be less likely to return to education. Our finding that cannabis use may have a negative association with educational attainment is not new (see for example Van Ours and Williams (2009)). However, we identify a new mechanism through which cannabis use may lead to lower educational attainment, namely through a lower likelihood of returning to education after first exiting education. An important question arising from our research is what our findings imply for the hazardous nature of early cannabis use, i.e. for the long run economic well-being of young men. In particular, does the negative association between cannabis use and wage rate in their first post education job translate into a permanent wage deficit, or do their wages catch up over time? And does accepting a job offer more quickly imply a poorer match and hence greater future job churn? Answering these question is left as an avenue for future research. What we can conclude from our analysis is that early cannabis use on an experimental basis does not seem to be hazardous as cannabis use for up to a year has no association whatsoever with early labor market experiences of young men. 


\section{References}

Abbring, J. H. and G. J. Van den Berg (2003). The non-parametric identification of treatment effects in duration models. Econometrica 71, 1491-1518.

Altonji, J., L. Kahn, and J. Speer (2014). Cashier or consultant? Entry labor market conditions, field of study, and career success. NBER working paper 20531.

Anderson, D. M., B. Hansen, and D. I. Rees (2013). Medical marijuana laws, traffic fatalities, and alcohol consumption. Journal of Law and Economics 56(2), 333-369.

Aston, E. R., J. Metrik, M. Amlung, C. W. Kahler, and J. MacKillop (2016). Interrelationships between marijuana demand and discounting of delayed rewards: Convergence in behavioral economic methods. Drug and Alcohol Dependence 169, 141-147.

Becker, G. and K. Murphy (1988). A theory of rational addiction. Journal of Political Economy 96(4), $675-700$.

Boccio, C. and K. Beaver (2017). Examining the influence of adolescent marijuana use on adult intelligence: Further evidence in the causation versus spuriousness debate. Drug and Alcohol Dependence 177, 199-206.

Bradford, A. C. and W. D. Bradford (2016). Medical marijuana laws reduce prescription medication use in Medicare Part D. Health Affairs 35, 1230-1236.

Bray, J. W. (2005). Alcohol use, human capital, and wages. Journal of Labor Economics 23, 279-312.

Cahuc, P., S. Carcillo, and A. Zylberberg (2014). Labor Economics, second edition. MIT Press. Cambidge, Mass.

Carliner, H., P. M. Mauro, Q. L. Brown, D. Shmulewitz, R. Rahim-Juwel, A. L. Sarvet, M. M. Wall, S. Martins, G. Carliner, and D. S. Hasin (2017). The widening gender gap in marijuana use prevalence in the u.s. during a period of economic change, 2002-2014. Drug and Alcohol Dependence 170, 5158.

Childs, E., J. A. Lutz, and H. de Wit (2017). Dose-related effects of Delta-9-THC on emotional responses to acute psychosocial stress. Drug and Alcohol Dependence 177, 136-144.

Clark, A. and A. Oswald (1994). Unhappiness and unemployment. Economic Journal 104, 648-659.

Cobb-Clark, D. and S. Schurer (2012). The stabilty of big 5 personality traits. Economic Letters 115, 11-15.

Cobb-Clark, D. and S. Schurer (2013). Two economists musings on the stabilty of locus of control. The Economic Journal 123, F358-F400.

Cutler, D. (1995). The incidence of adverse medical outcomes under prospective payment. Econometrica 63, $29-50$.

DellaVigna, S. and M. D. Paserman (2005). Job search and impatience. Journal of Labor Economics 23(3), $527-587$.

DeSimone, J. (2002). Illegal drug use and employment. Journal of Labor Economics 20(4), 952-977.

Elkins, R., S. Kassenboehmer, and S. Schurer (2017). The stability of personality traits in adolescence and young adulthood. Journal of Economic Psychology 60, 37-52.

Gaure, S., K. Roed, and T. Zhang (2007). Time and causality: A Monte Carlo assessment of the timing-ofevents approach. Journal of Econometrics 141(2), 1159 - 1195. 
Hall, W. (2015). What has research over the past two decades revealed about the adverse health effects of recreational cannabis use? Addiction 110(1), 19-35.

Hall, W. and R. L. Pacula (2003). Cannabis Use and Dependence: Public Health and Public Policy. Melbourne, Australia: Cambridge University Press.

Heckman, J. and B. Singer (1984). A method for minimizing the impact of distributional assumptions in econometric models for duration data. Econometrica 52, 271-320.

Kaestner, R. (1991). The effect of illicit drug use on the wages of young adults. Journal of Labor Economics 9(4), 381-412.

Kaestner, R. (1994a). The effect of illicit drug use on the labor supply of young adults. Journal of Human Resources 29(1), 126-155.

Kaestner, R. (1994b). New estimates of the effect of marijuana and cocaine use on wages. Industrial and Labor Relations Review 47(3), 454-470.

Kagel, J. J., R. C. Battalio, and C. G. Miles (1980). Marihuana and work performance: Results from an experiment. Journal of Human Resources 15(3), 373-395.

Lundborg, P., A. Nilsson, and D.-O. Rooth (2014). Adolescent health and adult labor market outcomes. Journal of Health Economics 37, 25 - 40.

McDonald, J., L. Schleifer, J. B. Richards, and H. de Wit (2003). Effects of THC on behavioral measures of impulsivity in humans. Neuropsychopharmacology 28, 1356-1365.

Moore, T. H., S. Zammit, A. Lingford-Hughes, T. R. Barnes, P. B. Jones, M. Burke, and G. Lewis (2007). Cannabis use and risk of psychotic or affective mental health outcomes: A systematic review. The Lancet $370(9584), 319-328$.

Mroz, T. A. (1999). Discrete factor approximations in simultaneous equation models: Estimating the impact of a dummy endogenous variable on a continuous outcome. Journal of Econometrics 92, 233-274.

Oreopoulos, P., T. von Wachter, and A. Heisz (2012). The short- and long-term career effects of graduating in a recession. American Economic Journal: Applied Economics 4, 1-29.

Park, J.-Y. and L.-T. Wu (2017). Prevalence, reasons, perceived effects, and correlates of medical marijuana use: A review. Drug and Alcohol Review 177, 1-13.

Register, C. and D. Williams (1992). Labor market effects of marijuana and cocaine use among young men. Industrial and Labor Relations Review 45(3), 435-448.

Sabia, J. and T. T. Nguyen (2018). The effect of medical marijuana laws on labor market outcomes. Journal of Law and Economics 61(3), 361-396.

Schaller, J. and A. H. Stevens (2015). Short-run effects of job loss on health conditions, health insurance, and health care utilization. Journal of Health Economics 43, 190-203.

Sferra, M. S., S. Thamotharan, and S. Fields (2015). Marijuana use and its relationship to impulsivity measured via delay discounting. Drug and Alcohol Dependence 146, e34-e117.

Van Ours, J. C. (2006). Cannabis, cocaine and jobs. Journal of Applied Econometrics 21(7), 897-917.

Van Ours, J. C. (2007). The effect of cannabis use on wages of prime age males. Oxford Bulletin of Economics and Statistics 69(5), 619-634. 
Van Ours, J. C. and J. Williams (2009). Why parents worry: Initiation into cannabis use by youth and their educational attainment. Journal of Health Economics 28, 132-142.

Van Ours, J. C. and J. Williams (2011). Cannabis use and mental health problems. Journal of Applied Econometrics 26, 1137-1156.

Van Ours, J. C. and J. Williams (2012). The effects of cannabis use on physical and mental health. Journal of Health Economics 31, 564-577.

Van Ours, J. C. and J. Williams (2015). Cannabis use and its effects on health, education and labor market success. Journal of Economic Surveys 29(5), 993-1010.

Van Ours, J. C., J. Williams, D. Fergusson, and L. J. Horwood (2013). Cannabis use and suicidal ideation. Journal of Health Economics 32(3), 524-537.

Volkow, N. D., J. M. Swanson, A. E. Evins, L. E. DeLisi, M. H. Meier, R. Gonzalez, M. A. P. Bloomfield, H. V. Curran, and R. Baler (2016). Effects of cannabis use on human behavior, including cognition, motivation, and psychosis: A review. JAMA Psychiatry 73, 292-297.

Yang, Z., D. Gilleskie, and E. Norton (2009). Health insurance, medical care and health outcomes: A model of elderly dynamics. Journal of Human Resources 44, 47-114. 
Table 1: Summary Statistics

\begin{tabular}{lllll}
\hline & Full & \multicolumn{3}{l}{ Used cannabis } \\
& Sample & No & Yes & Difference \\
\hline Cannabis use ever & 0.63 & 0.35 & 1.00 & $0.65^{* * *}$ \\
Cannabis use before entering unemployment & 0.43 & 0.00 & 1.00 & - \\
Cannabis use before job finding & 0.49 & 0.10 & 1.00 & $0.90^{* * *}$ \\
Duration of cannabis use before entering unemployment & 1.63 & 0.00 & 3.82 & $3.82^{* * *}$ \\
Duration of cannabis use lifetime & 6.35 & 4.25 & 7.35 & $3.10^{* * *}$ \\
Age left school & 18.73 & 18.59 & 18.92 & $0.33^{* *}$ \\
Highest grade completed & 12.13 & 12.04 & 12.24 & $0.20^{* * *}$ \\
Started work & 0.79 & 0.76 & 0.82 & $0.06^{* * *}$ \\
Duration till found job (quarters) & 4.26 & 4.38 & 4.09 & -0.30 \\
Duration till found job (quarters) | work & 3.64 & 3.82 & 3.42 & $-0.40^{*}$ \\
Starting hourly wage | work & 9.14 & 9.12 & 9.17 & 0.05 \\
Back to school & 0.18 & 0.21 & 0.14 & $-0.07^{* * *}$ \\
Duration back to school (quarters)| back to school & 4.12 & 4.23 & 3.92 & -0.30 \\
\hline
\end{tabular}

Note: The sample consists of 3885 males; ***, **,* indicates significant at a 1, 5, 10 percent level. 
Table 2: Parameter estimates for cannabis use

\begin{tabular}{|c|c|c|c|c|c|c|}
\hline & \multicolumn{2}{|c|}{ Job Finding } & \multicolumn{2}{|c|}{ Starting Wage } & \multirow{2}{*}{$\begin{array}{r}-\log \mathrm{L} \\
7199.8\end{array}$} & \multirow{2}{*}{$\begin{array}{c}\text { Mass-points } \\
2\end{array}$} \\
\hline a1. Exogenous cannabis & 0.13 & $(3.0)^{* *}$ & - & - & & \\
\hline a2. Exogenous cannabis & - & - & -0.019 & $(1.8)^{*}$ & 597.9 & 2 \\
\hline b. Correlated cannabis & 0.08 & $(1.7)^{*}$ & -0.017 & $(1.5)$ & 21075.1 & 12 \\
\hline c. Education & & & & & 21073.1 & 12 \\
\hline Less than high school & 0.20 & $(2.5)^{* *}$ & -0.009 & $(0.4)$ & & \\
\hline High school graduate & 0.02 & $(0.4)$ & -0.019 & $(1.2)$ & & \\
\hline College & 0.02 & $(0.2)$ & -0.027 & $(1.3)$ & & \\
\hline d. Age at uptake & & & & & 21074.2 & 12 \\
\hline By age 15 & 0.06 & $(1.0)$ & -0.015 & $(1.1)$ & & \\
\hline At age 16 or 17 & 0.12 & $(1.7)^{*}$ & -0.028 & $(1.7)^{*}$ & & \\
\hline At age 18 or older & 0.09 & $(1.0)$ & 0.001 & $(0.04)$ & & \\
\hline e. Duration of use & & & & & 21072.1 & 12 \\
\hline Up to 1 year & -0.07 & $(0.9)$ & -0.004 & $(0.2)$ & & \\
\hline More than 1 year & 0.12 & $(2.4)^{* *}$ & -0.020 & $(1.7)^{*}$ & & \\
\hline
\end{tabular}

Note: All estimates contain the same explanatory variables as in Appendix Tables C.1 (for cannabis) and C.2 (for job finding, back to school and wages). Absolute t-statistics in parentheses; ${ }^{* *}\left({ }^{*}\right)$ indicates significant at a 5 (10) percent level.

\begin{tabular}{llllcc}
\hline \multicolumn{6}{l}{ Distribution of Unobserved Heterogeneity - Panel b } \\
\hline \multirow{2}{*}{ Wages } & Cannabis & Cannabis & \multicolumn{2}{l}{ Job Finding Rate } \\
& Starting Rate & Quit Rate & High & Low & Total \\
\hline High & Positive & High & 0.6 & 1.1 & 1.7 \\
High & Positive & Low & 1.2 & 0.3 & 1.5 \\
High & Zero & - & 0.7 & 0.7 & 1.4 \\
\hline Low & Positive & High & 30.1 & 5.4 & 35.5 \\
Low & Positive & Low & 30.5 & 4.3 & 34.8 \\
Low & Zero & - & 18.7 & 6.4 & 25.1 \\
\hline Total & & & 81.7 & 18.3 & 100.0 \\
\hline
\end{tabular}


Table 3: Parameter estimates for cannabis use: competing risk for return to school or find a job

\begin{tabular}{|c|c|c|c|c|c|c|c|c|}
\hline & \multicolumn{2}{|c|}{$\begin{array}{c}\text { Job } \\
\text { finding }\end{array}$} & \multicolumn{2}{|c|}{$\begin{array}{c}\text { Back to } \\
\text { school }\end{array}$} & \multicolumn{2}{|c|}{$\begin{array}{c}\text { Starting } \\
\text { wage }\end{array}$} & \multirow{4}{*}{$\frac{-\log \mathrm{L}}{21072.1}$} & \multirow{4}{*}{$\begin{array}{c}\text { Mass } \\
\text { points }\end{array}$} \\
\hline & & & & & & & & \\
\hline Up to 1 year & -0.07 & $(0.9)$ & - & - & -0.004 & $(0.2)$ & & \\
\hline More than 1 year & 0.12 & $(2.4)^{* *}$ & - & - & -0.020 & $(1.7)^{*}$ & & \\
\hline b. With return to school & & & & & & & 23427.9 & 13 \\
\hline Up to 1 year & -0.09 & $(1.0)$ & -0.38 & $(1.8)^{*}$ & -0.001 & $(0.4)$ & & \\
\hline More than 1 year & 0.17 & $(2.9)^{* *}$ & -0.47 & $(3.1)^{* *}$ & -0.023 & $(2.0)^{* *}$ & & \\
\hline c. Ignore job if return to school & & & & & & & 23730.2 & 12 \\
\hline Up to 1 year & -0.01 & $(0.1)$ & -0.42 & $(2.4)^{* *}$ & -0.006 & $(0.3)$ & & \\
\hline More than 1 year & 0.28 & $(4.7)^{* *}$ & -0.46 & $(3.8)^{* *}$ & -0.026 & $(2.0)^{* *}$ & & \\
\hline d. Full time job & & & & & & & 24143.5 & 12 \\
\hline Up to 1 year & 0.09 & $(1.0)$ & -0.56 & $(2.9)^{* *}$ & -0.015 & $(0.7)$ & & \\
\hline More than 1 year & 0.26 & $(4.4)^{* *}$ & -0.58 & $(4.3)^{* *}$ & -0.028 & $(2.2)^{* *}$ & & \\
\hline
\end{tabular}

Note: All estimates contain the same explanatory variables as in Appendix tables C.1 (for cannabis) and C.2 (for job finding, back to school and wages). Absolute t-statistics in parentheses; ${ }^{* *}(*)$ indicates significant at a $5(10)$ percent level.

\begin{tabular}{lllcccc}
\hline \multicolumn{3}{l}{ Distribution of Unobserved Heterogeneity - Panel b } \\
\hline & & & \multicolumn{3}{c}{ Job Finding Rate } & \\
\cline { 4 - 6 } & & & High & Low & Low & \\
Wages & Cannabis & Cannabis & \multicolumn{2}{l}{ Back to School Rate } & \\
\cline { 4 - 6 } High & Positive & High & - & 5.5 & - & 5.5 \\
High & Positive & Low & 1.0 & 1.4 & - & 2.4 \\
High & Zero & - & 0.6 & - & 0.6 & 1.2 \\
\hline Wages & Positive & High & 29.4 & - & 3.2 & 32.6 \\
Wages & Positive & Low & 28.4 & 4.2 & 1.0 & 33.6 \\
Wages & Zero & - & 17.0 & 4.7 & 3.0 & 24.7 \\
\hline Total & & & 76.4 & 15.8 & 7.8 & 100.0 \\
\hline
\end{tabular}




\section{University Library}

\section{- $\mathrm{M}$ IIN E R VA A gateway to Melbourne's research publications}

Minerva Access is the Institutional Repository of The University of Melbourne

Author/s:

Williams, J;van Ours, J

Title:

Hazardous or Not? Early Cannabis Use, and the School to Work Transition of Young Men

Date:

2020-10-01

Citation:

Williams, J. \& van Ours, J. (2020). Hazardous or Not? Early Cannabis Use, and the School to Work Transition of Young Men. Health Economics, 29 (10), pp.1148-1160. https:// doi.org/10.1002/hec.4125.

Persistent Link:

http://hdl.handle.net/11343/241617 